drochloric acid. The contents of the beaker were then boiled, after the first action was completed, until the chromate and permanganate rere reduced. An addition of ro cc. of nitric acid ( 1.20 ) followed, and the analysis was carried out exactly as given for chromium-nickel stets. using twenty-four grams of citric acici. The results obtained are given in Tabie 4. Sulphuric acid was added as in the process for steels.

$$
\text { TABI, I: } 4 \text {. }
$$

\begin{tabular}{lcr}
\multicolumn{3}{c}{ I'er centh of Metals. } \\
Ni. & Mn & C. \\
+1 & 20 & 10 \\
20.6 & 40 & 20 \\
15 & 60 & 15 \\
1.5 & 95.5 & 1 \\
0.25 & 94.9 & 2 \\
& 94.9 & 2
\end{tabular}

\begin{tabular}{|c|c|c|}
\hline lic & $\begin{array}{l}\text { Frand of rickel. } \\
\text { Adided. }\end{array}$ & Fomuli. \\
\hline $3^{\circ}$ & 0.2059 & $0.205^{8}$ \\
\hline 20 & 0.1029 & 0.10225 \\
\hline in & 0.0750 & $(1,0752$ \\
\hline 2 & 0.00749 & $0.00 \div 62$ \\
\hline 2.9 & 0.00124 & 0.00122 \\
\hline 4 & Xone & 0.00006 \\
\hline
\end{tabular}

Table 4 gives evidence of the fact that nickel can be accurately determined in the presence of large percentages of chromium and manganese, if the conditions herein given are carefully observed. In the hands of a practised operator 10 difficulty was experienced in the analysis when as much as 95 per cent. of manganese was in solution with but 0.25 per cent. of nickel.

IABORATORY OI PAKK STTEEL CO. WORKSO

'THE CRTCLIJEL S'TEEL. CO. OH AMFRICA.

\title{
THE DETERMINATION OF SILICA AND ALUMINA IN IRON ORES.
} BY G. W. DEAX.

Received April 22, 190-

Further experience with the method which was described in this Journal last year has led to its modification in two or three important particulars. It has been found that the ore may be ignited directly instead of separating and igniting the residue from digestion with hydrochloric acid. It has also been found that a porcelain crucible is the most suitable for the igniton, since the ore is less liable to be overheated and the alumina rendered insoluble. When the determination of alumina is not required, the use of stannous chloride aids greatly in dissolving the ore. It has also been found that by heating the ore with sulphur it is partly reduced in such a manner that it is more easily soluble in hydrochloric acid and the whole method can be used when it is desired to determine both silica and alumina. The methods which are now used are as follows:

Determination of Sulica Alone. Weigh $0.5 \mathrm{~g}$. of the finely pulverized ore ( $100 \mathrm{mesh}$ ), transfer to a $20 \mathrm{cc}$. porcelain crucible, cover and heat over a Dangler burner until the contents of the crucible are dull red, raise the temperature for a few seconds and then renove the crucible from the source of the heat. The whole operation should take not more than two or three minutes. Transfer the ignited ore when cold to a beaker, add $20 \mathrm{cc}$. strong hydrochloric acid containing one gram of stannous chloride

${ }^{1}$ This Jour11a1, 28, 882 . 
in $225 \mathrm{cc}$. Boil vigorously until solution is apparently complete and for five or ten minutes longer. Twenty or thirty minutes will usually be enough. If the ore is very difficult to dissolve, a stronger solution of stannous chloride, or more of the same solution may be used. Dilute slightly, filter, and wash thoroughly first with dilute hydrochloric acid and then with water. Ignite and weigh the silica as usual.

2. Determination of both Silica and Alumina. Weigh $0.5 \mathrm{~g}$. of the finely pulverized ore ( 100 mesh), transfer to a $20 \mathrm{cc}$. porcelain crucible and place on top 0.25 to $0.40 \mathrm{~g}$. of sulphur, heat gradually until the ore is dull red and then raise the temperature slightly for ten seconds. Transfer to a beaker, pulverize the mass with a glass rod, add $25 \mathrm{cc}$. of hydrochloric acid and boil vigorously for fifteen minutes. Then add enough nitric acid to clear the solution and decompose the sulphides and boil vigorously for another five or ten minutes, repeating the addition of nitric acid and boiling if required. If dark particles remain undissolved after this treatment, it is probable that further treatment will not decompose them. Dilute, filter, wash and determine the silica, as before, and in the filtrate determine the alumina by any one of the various methods which are suitable. In this method the ignited mass is treated with hydrochloric acid first to gain the advantage of the reducing action of the hydrogen sulphide liberated from the sulphide of iron formed by the action of the sulphur. If the nitric acid is added at first, the advantage of this reducing action, is lost and the oxides of iron are often very difficult to dissolve.

The methods have been applied to the determination of silica in the following ores: (1) Arizona hematite; (2) Wyoming low grade hematite; (3) Alabama limonite; (4) Alabama hematite; (5) Maguanite from Llano County, Texas; (6) Michigan Magnetite; (7) Michigan hematite; (8) Mesabi limonite; (9) Mesabi decomposed hematite; (10) Swedish hematite; (I I) Swedish magnetite; (I 2) Highly aluminiferous hematite from Baraboo iron district; (I3) Hematite from Port Arthur field in Canada; (14) Bog iron from Nova Scotia. The results are as follows:

\begin{tabular}{|c|c|c|c|}
\hline & $\begin{array}{l}\text { Deter } \\
\text { Per cent. silica }\end{array}$ & $\begin{array}{l}\text { lious ate in duplicate. } \\
\text { Pe: cent. silica by Hydro. }\end{array}$ & \\
\hline & by $\mathrm{Na}_{2} \mathrm{CO}$, fusion & fluoric acid method & above method \\
\hline I. & $\mathrm{I} 2.06-\mathrm{I} 2.20$ & 12.08 - 2.10 & $12.09-12.13$ \\
\hline 2. & $21.27-21.22$ & 2 I.II-2Г. 20 & $21.26-2 \mathrm{I} .23$ \\
\hline 3 . & $13.77-13.68$ & $13.69-13.72$ & $13.73-13.62$ \\
\hline 4. & I I. $99-$ I I.S2 & I1.: $8-$ r I.94 & II. $92-11.83$ \\
\hline 5. & $14.28-14.33$ & $14.32-14.3 \mathrm{I}$ & $14.36-14.4 \mathrm{I}$ \\
\hline 6. & $9.91-9.99$ & $9.82-9.89$ & $9.80-9.8 \mathrm{I}$ \\
\hline 7. & $10.55-10.40$ & $10.49-\cdots$ & $10.50-10.52$ \\
\hline 8. & $8.02-8.00$ & $8.15-8.10$ & $7.99-x .08$ \\
\hline 9. & $17.82-17.74$ & $17.85-17.77$ & $17.86-17.88$ \\
\hline Lo. & $7.09-7.13$ & $7.00-7.04$ & $7.06-7.01$ \\
\hline I I. & $6.72-6.81$ & $6.72-6.67$ & $6.74-6.77$ \\
\hline 12 . & $31.12-35.18$ & $31.09-31.12$ & $31.08-31.11$ \\
\hline I 3. & $4.44-4.52$ & $4.40-4.52$ & $4.38-4.40$ \\
\hline 14. & $2.06-2.05$ & $2.08-2.03$ & $2.09-2.00$ \\
\hline
\end{tabular}


It is evident from the above that the method gives accurate results when applied to a great variety of ores.

FAC CLAIRE, Wiscoxisin.

\title{
A NEW SHAKING DEVICE FOR THE CHEMICAL LABORATORY.
}

\author{
IMY J M. CABr. \\ Received May 25,1 ço:
}

Among the various pieces of apparatus yoing to make up the equipment of the modern laboratory, it is the purpose of this article to describe the latest appliance, in the shape of a sliaking device. It was designed and is particularly adapted for the purpose of hastening the precipitation of phosphorus by the well-known and almost exclusively used molybdic acirl method, and in the solution of steels or pig irons for carbon combustion. But it is equally useful where agitation is desired in a flask for either dissolving or precipitating. As can be seen from the photograph, it consists of a frame supporting a vertical shaft, which is revolved by a six-inch pulley wheel. The upper part of the shaft is bent slightly from the perpendicular. Encircling the bent portion of the shaft is a hub which in turn supports a flat disc on which the flasks to be shaken are attached. The hub and disc are prevented from turning, when the shaft is revolved, by suitable teeth on the underside of the hub meshing into corresponding teeth on the top of the supporting frame.

On revolving the shaft the motion of the disc is ideal for the purpose intended, and can be best likened to the simultaneous pitching and tossing of the deck of a ship in a tumultuous sea. With each revolution of the shaft a wave travels around the flask or flasks on the disc exactly as in hand shaking, and by increasing or diminishing the number of revolutions the number and intensity of the ware movement is controlled. To obtain the maximum agitation and still retain the solutions in the flasks, without corking, from one hundred to one hundred and forty revolutions per minute has been found satisfactory. The disc is made to hold six flasks, any one of which can be placed in or removed from the machine in a fraction of a second. The gripping device is movable, up or down, enabling it to be quickly adjusted to hold any size flask from a six ounce to a twenty-four ounce Florence or Erlenmeyer. The electrical power required to operate it is twelve hundredths of an ampere on $250 \mathrm{rolts}$, about the equivalent of the one twenty-fifth horse power, or less than the average desk fan motor is consuming, so that with the proper counter shaft to give the desired number of revolutions, any source of power may be used

Heat can be applied to the apparatus if desired by means of a circular 